\title{
Reliability of an interactive sport-specific choice reaction time device
}

\author{
Chih-Yin Tai ${ }^{1}{ }^{*}$, Kristy R Crowley ${ }^{3}$, Brandon D Spradley ${ }^{2}$, Laura R Carson ${ }^{1}$, Paul H Falcone ${ }^{1}$, Enrico N Esposito ${ }^{4}$, \\ Michael P Kim ${ }^{1}$, Eric R Serrano ${ }^{1}$, Jordan R Moon ${ }^{1,2}$ \\ From International Society of Sports Nutrition: 10th Annual ISSN Conference and Expo \\ Colorado Springs, CO, USA. 14-15 June 2013
}

\section{Background}

The purpose of this study was to establish the reliability of an interactive choice reaction testing device (Makoto II Arena) to determine the efficacy of the device as it relates to the field of strength and conditioning and sports nutrition research, as well as to determine what protocols are the most reliable in regards to sports specific movements and time.

\section{Methods}

Twelve recreationally trained males participated in Part $a$, which consisted of two visits (mean +/- SD, $3.7+/$ 1.3 days); a familiarization testing day $\left(\mathrm{V} 1_{\mathrm{a}}\right)$, followed by a subsequent testing day $\left(\mathrm{V}_{\mathrm{b}}\right)$, and was conducted over a three week investigation period $(28+/-5 \mathrm{yr}, 178+/-9$ $\mathrm{cm}, 79.15+/-15.7 \mathrm{~kg}, 17.5+/-6.6 \%$ body fat). Part $a$ was composed of nine choice reaction time testing protocols, including single step audio (CRA); single step visual (CRV); 15/30s single tower unidirectional [CRS(15s) (30s)]; 15/30s two tower lateral-directional [CRL(15s), (30s)]; $15 / 30$ s three tower multi-directional [CRM (15s), (30s)]; and a three tower, 2-minute stick hit test (stick hits). Seventeen recreationally trained males participated in Part $b$, which consisted of two visits $(4.9+/-1.9$ days $)$ following a familiarization day $\left(\mathrm{V} 1_{\mathrm{b}}\right.$ and $\left.\mathrm{V} 2_{\mathrm{b}}\right)$, and was conducted over a two week investigational period $(21.5+/$ $4.7 \mathrm{y}, 181.1+/-6.1 \mathrm{~cm}, 85.2+/-17 \mathrm{~kg}, 14.5+/-11 \%$ body fat). Part $b$ comprised the same choice reaction time testing protocols as Part $a$. Part $c$ consisted of a pooled mean of 62 tests taken from Part $a$ and Part $b$, which examined data within choice reaction testing days between $\mathrm{V} 1_{\mathrm{a}}, \mathrm{V} 2_{\mathrm{a}}$, $\mathrm{V} 1_{\mathrm{b}}$, and $\mathrm{V} 2_{\mathrm{b}}$, except the 2-minute Stick Hits data.

${ }^{1}$ Sports Science Center Research Institute, MusclePharm, Inc., Denver, CO, USA

Full list of author information is available at the end of the article

\section{Results}

Mean (+/-SD) time (seconds) values for Part $a$, Part $b$, and Part $c$ were $0.87,0.91$ and 0.86 for Day/Trial 1 respectively, and $0.81,0.89$, and 0.85 for Day/Trial 2 which resulted in no significant differences from Day/Trial 1 to Day/Trial 2 for Part $a, b$, and $c$ ( $\mathrm{p}>0.05$ ). However, all times between testing days/trials decreased ( $a$ : $-0.071 \mathrm{sec}$, $b$ : -0.021 sec, $c:-0.010)$. Differences in days from Part $b$ $(-0.02 \mathrm{sec})$ and Trials for Part $c(-0.01 \mathrm{sec})$ resulted in similar findings, suggesting a familiarization session between testing days may result in similar reliability to that of within-day trials $(\mathrm{p}=1.00)$. Two testing batteries showed a significant decrease in time between Day 1 and Day 2 after familiarization: CRL15 (Mean difference $=-0.07, \mathrm{p}=0.036$ ) and CRM30 (Mean difference $=-0.05, \mathrm{p}=0.022$ ).

\section{Conclusions}

A day of familiarization improved the reliability of all tests. Single step, 30 second, and 15 second tests appear to be reliable. Furthermore, the current study suggests that a "predominantly" upper body unidirectional choice reaction test lasting 30 seconds may be more reliable than a test which utilizes multi-joint or multi-direction functioning lasting 15 seconds or less, however, the reliability within and between days appears to be no different for the tests used in the current investigation suggesting the device and methods used in the current investigation are acceptable for use in strength and conditioning and sports nutrition research.

\section{Acknowledgements}

This study was funded by MusclePharm, Inc., Denver, CO, USA

\section{Authors' details}

${ }^{1}$ Sports Science Center Research Institute, MusclePharm, Inc., Denver, CO, USA. ${ }^{2}$ Department of Sports Exercise Science, United States Sports Academy, Daphne, AL, USA. ${ }^{3}$ Department of Sport Management, University College of 
Northern Denmark, Aalborg, Denmark. ${ }^{4}$ Department of Human Performance and Exercise Science, University of Mobile, Mobile, AL, USA.

Published: 6 December 2013

doi:10.1186/1550-2783-10-S1-P18

Cite this article as: Tai et al:: Reliability of an interactive sport-specific

choice reaction time device. Journal of the International Society of Sports Nutrition 2013 10(Suppl 1):P18.

Submit your next manuscript to BioMed Central and take full advantage of:

- Convenient online submission

- Thorough peer review

- No space constraints or color figure charges

- Immediate publication on acceptance

- Inclusion in PubMed, CAS, Scopus and Google Scholar

- Research which is freely available for redistribution 